\title{
swivel
}

\section{ANDREW COLOPY}

Rice University

Set among the sublime Icelandic landscape is a series of subtly enigmatic figures. Each a little different, their faceted mass responds to the environment at multiple scales. Adapting to immediate context and global orientation, the cabins maintain a predominant east-west axis while pivoting perpendicular or parallel to the approaching trail. The strategy affords a consistent southern facing roof for active and passive solar gain while serving as a means of cardinal orientation to hikers. The end of each cabin addresses an intermediate scale, swiveling to gesture toward the next cabin along the trail, further orienting hikers from the exterior but also from within as they gaze out the singular windows in the attenuated ends of each cabin, reflecting on either where they've come from or where they're headed. But this swivel also formally connects the larger network of cabins, making them both unique and interdependent while further reflecting the extent of the national territory they inhabit.

As objects in the landscape, the cabins are set apart and responsive to their environment, yet given the dark exterior, they appear equally as voids, background to the strong saturation and figuration of the surrounding scene. The exterior rain screen is continuous across roof and wall, reinforcing a volumetric quality while absorbing the warmth of the sun. Made from charred wood, the material is also exceptionally durable and sustainable while familiar to the local context. Aesthetically integrated, photovoltaics and rainwater collection and storage help the cabins be autonomous, and heavily insulated SIP construction makes them highly energy efficient, easily transported and assembled.

Inside, the dark exterior gives way to a bright, continuous plywood surface punctuated by spots of color, a reference to the bold exterior coloration of many vernacular cabins. Fold down bunks for 10 along the long high wall fold up to make extra space to gather in an efficient 350sf (32.5sm). 

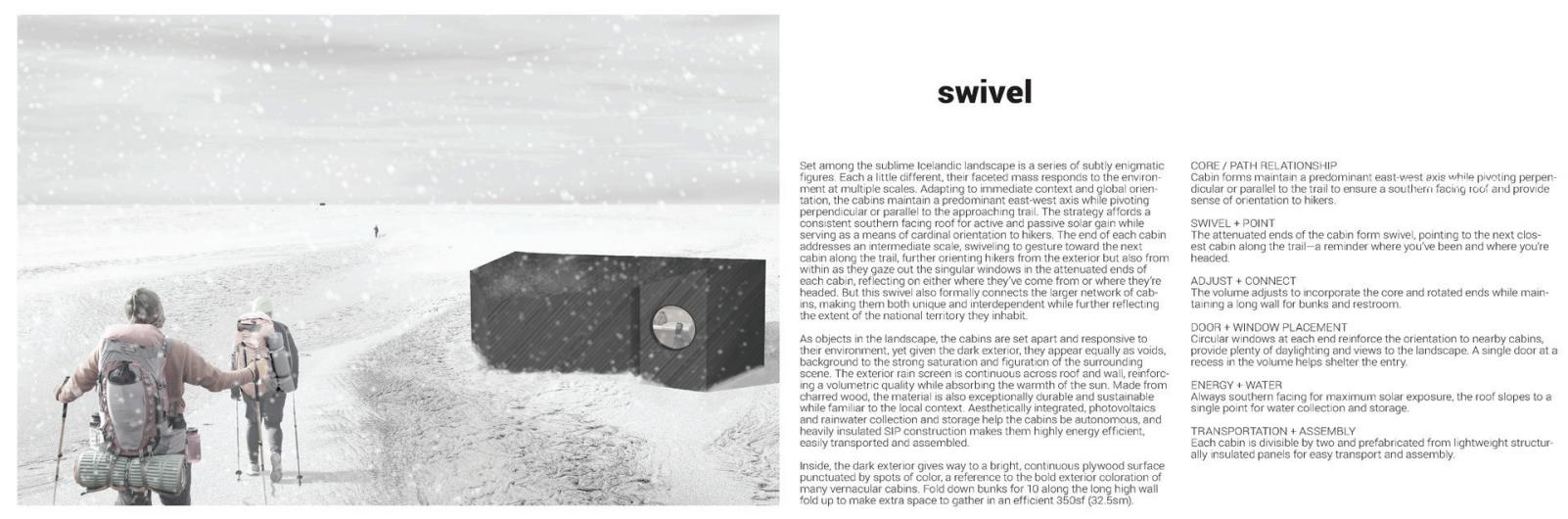

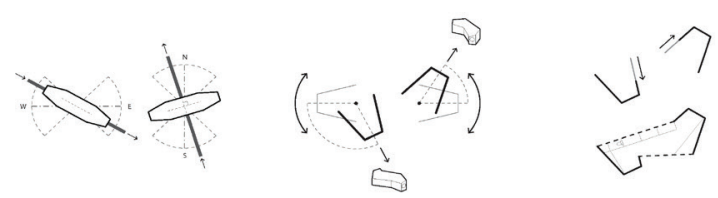
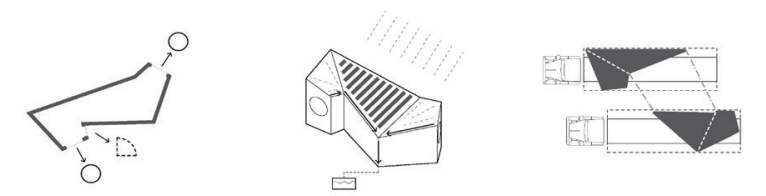

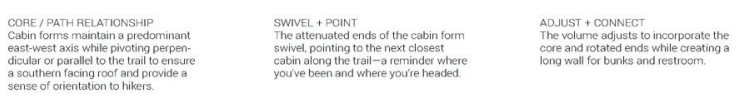

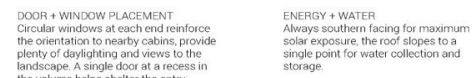
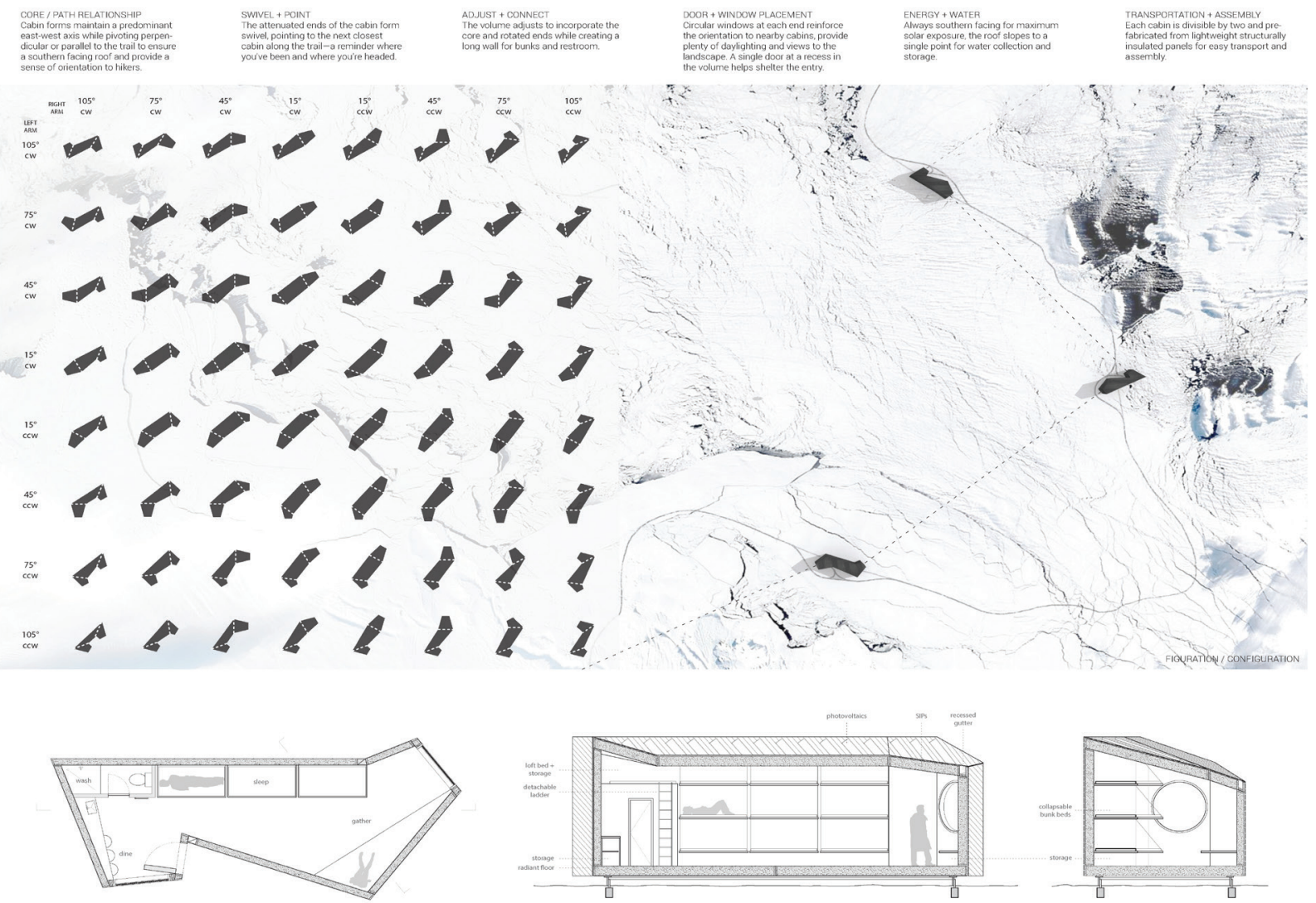

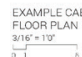
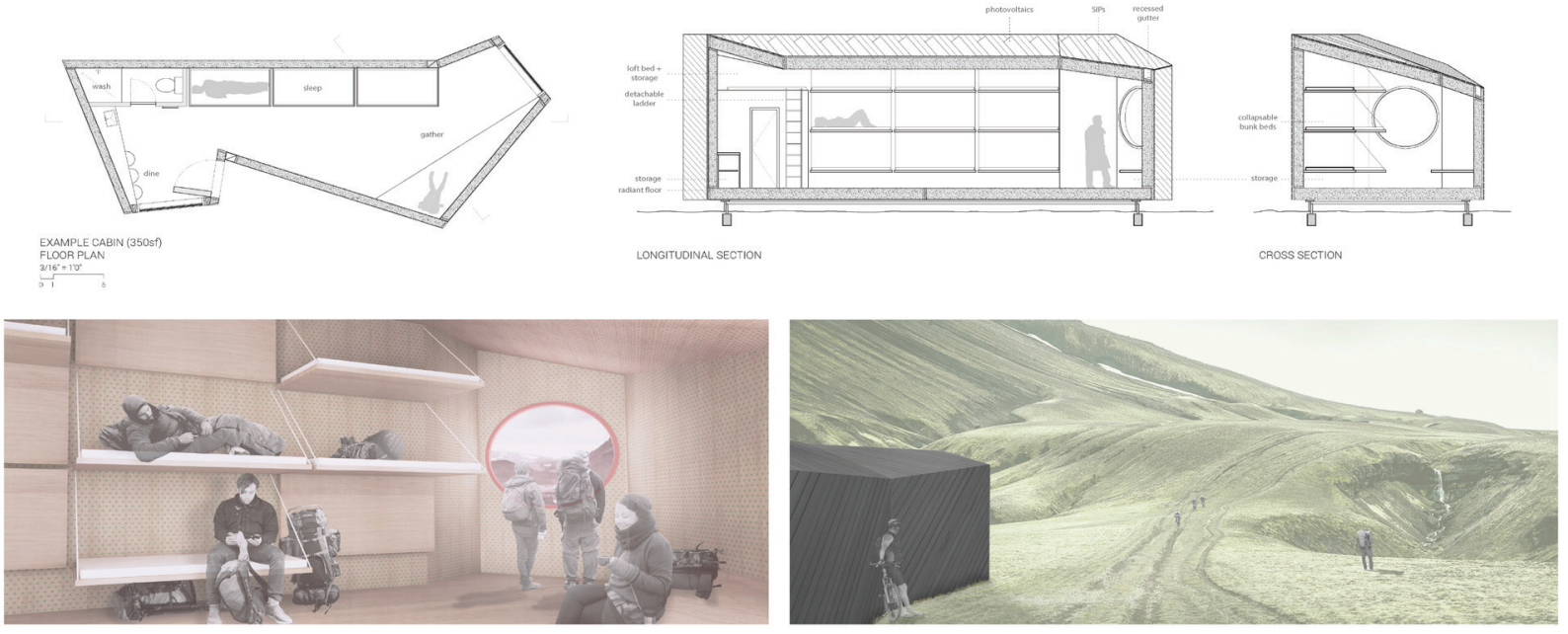